\title{
Stereological Study of the Protective Role of Curcumin on Histological Changes of Seminal Vesicle in Mice Following Treatment with Sodium Arsenite
}

\author{
Monireh Mahmoodi', Malek Soleimani Mehranjani ${ }^{r}$
}

Received: 20 Feb, 2017; Accepted: 27 Apr, 2017

\begin{abstract}
Background \& Aims: Sodium arsenite causes oxidative stress and endocrine disorders in the reproductive system. The aim was to investigate the protective role of curcumin as an antioxidant on the seminal vesicle tissue in adult mice treated with sodium arsenite.

Materials \& Methods: Adult male Naval Medical Research Institute (NMRI) mice were randomly divided into 4 groups (six mice per group) including control, Sodium arsenite (5mg/kg/day b.w.), Curcumin (15mg/kg/day b.w.) and Sodium arsenite + Curcumin. After 5 weeks of treatment, the mice were anesthetized and the seminal vesicles were removed and weighed. This followed by evaluating of the mean total volume of seminal vesicle and the mean volume of parenchyma, vesicular fluid, epithelial cells, vessels, connective and muscular tissues using stereological techniques. The results analyzed statistically by one-way ANOVA and Tukey's test and the means were considered significantly different at $\mathrm{p}<0.05$.

Results: A significant reduction in the mean total volume of seminal vesicle and mean volume of vesicular fluid ( $p<0.001)$, and a significant increase in the mean volume of connective tissue $(\mathrm{p}<0.001)$ were seen in the sodium arsenite group when compared to the control ones. The mentioned parameters were compensated to the control level in the sodium arsenite + curcumin group.

Conclusion: Our results showed that curcumin could prevent the adverse histological changes induced by sodium arsenite treatment on the seminal vesicle in mice.
\end{abstract}

Keywords: Sodium arsenite, Curcumin, Seminal vesicles, Stereology, Mice

Address: Department of Biology, Faculty of Science, Arak University, Arak 38156-8- 8349, Iran.

Tel: (+98)9188641048

Email: m-mahmoodi@araku.ac.ir

${ }^{1}$ Assistant Professor of Developmental Biology, Arak University, Arak, Iran (Corresponding Author)

${ }^{2}$ Professor of Embryology \& Histology, Arak University, Arak, Iran 


\section{Introduction}

Arsenic is an inorganic compound widely distributed in the environment (1) and is used in the production of pesticides, fungicides, wood preservatives, metallurgy, glass (2), coal-fired power plants and cosmetics (1). So, arsenic can be released into the atmosphere from natural sources and by human industrial activities and can pollute the water, air and soil $(2,3)$. Arsenite (trivalent form) and arsenate (pentavalent form) are among the most common forms of arsenic; in the meantime, trivalent arsenic has a greater potential for toxicity compared to the pentavalent (2). Due to the high reactivity of sodium arsenite to endogenous thiol groups, especially dithiols, it is being considered among the most harmful arsenic compounds (4) which damages DNA and ultimately changes cell performance through the production of Reactive Oxygen Species (ROS) and oxidative stress $(6,5)$. Arsenic is a potential occupational carcinogen and recently is known as one of the predominant causes of disorders such as keratosis, peripheral neuropathy, vascular disease and male infertility (7). Studies have shown that arsenic toxicity in laboratory animals increases the lumen of the seminiferous tubules, reduces sperm storage, reduces the number of mature sperm, reduces sperm viability and motility and thus reduces the ability of sperm and oocytes $(7,8,9)$. According to the researches, arsenic can impair of male reproductive system through the inhibition of spermatogenesis, decreasing the activity of antioxidant defense system in the testes, reducing the amount of testosterone and gonadotropins and reducing testis weight and appendix sexual organs $(1,10,11)$. Reports also showed decreased seminal vesicle weight of animals treated with sodium arsenite $(1,2,3)$ In addition, high levels of radioactive arsenic have been found in the epididymis and the seminal tract of rodents $(2,7)$.
Curcumin or $\mathrm{C} 12 \mathrm{H} 20 \mathrm{O} 6$ is a polyphenol and the most active component of curcuma longa (12) which acts as a free radical cleansing and is considered as an effective antioxidant against oxidative stress damage which can significantly inhibit the production of reactive oxygen species both in Vivo and in Vito (13, 14). Antioxidant properties of curcumin and male reproductive system protection against oxidative stress and environmental pollutants such as nitrates, aflatoxins, cadmium, chromium, acrylamide and lindane have been noted in many studies (14-19). However, few studies have reported the effects of curcumin on the seminal vesicle, indicating its effect in offsetting the adverse effects of metronidazole (20) and Chrome on seminal vesicle (14). According to the studies, no report has been provided about the effect of curcumin on rat's seminal vesicle treated with sodium arsenite yet. Since the seminal vesicle is a male sexual organ and its function is to secrete a part of semen and plays an important role in activating of sperm and sperm survival in the vagina acidic environment (21, 22 ), the aim of this study was to investigate the protective effect of curcumin as a powerful antioxidant on the seminal vesicle tissue of mice after treatment with sodium arsenite using stereological technique.

\section{Materials and Methods}

\section{Animals:}

In this experimental study, adult male NMRI rats with an average weight of $31.05 \pm 2.25 \mathrm{~g}$ were purchased from the Institute Pasteur Institute of Iran Tehran and were kept at the Animal House of Arak University for 12 hours in darkness, 12 hours in light and at the temperature of $21 \pm 2{ }^{\circ} \mathrm{C}$ with free access to food and water. The mice were randomly divided into 4 groups ( $\mathrm{n}=6$ per group) of control, sodium arsenite (5 $\mathrm{mg}$ per $\mathrm{kg}$ of body weight per day, Merck of Germany), Curcumin-treated group (at a dose of $15 \mathrm{mg}$ per kg of body weight per day, Sigma Corporation of 
America) and sodium arsenite-curcumin treated group. The treatment was performed by intraperitoneal injection for 5 weeks. The doses used in this study were selected according to the studies $(23,24)$.

\section{Histological and stereological studies:}

After 5 weeks of treatment, mice were anesthetized by diethyl and seminal vesicles of both sides were taken out after opening the lateral anterior wall of the abdomen and their weights were measured. Then the primary volume (Vprimary) of seminal vesicle was measured by dipping method and tissues were placed in Bowen fixative to prove for 24 hours (20). In this method, a beaker containing distilled water was weighed by scales (W1), seminal vesicle was then floated inside by a very thin thread and the beaker containing seminal vesicle was re-weighed (W2). Since the density of distilled water was one, the weight difference was considered as the initial volume in $\mathrm{cm}^{3}$ of the seminal vesicle. Then, isotropic uniform random (IUR)) parts of seminal vesicle tissue were prepared $(20,25)$ using Orientator method $(25,26)$. For this purpose, each lobe of the gland had been laid on phi (ф) with 10 equal distances. A random number was selected between zero and 10 and tubers were cut in two halves along the selected number. Then the cut surface of one of the halves was put along and the other was tangent to theta $(\theta)$ of axis $0-0$ which was divided into 10 unequal parts and were cut along a randomly selected number. So that each half is divided into slabs and total 9-12 slabs were collected from seminal vesicles of each mouse. Round pieces of slabs of seminal vesicle were prepared by trocar in order to calculate the shrinkage. Two randomized diameter of round parts of gland were measured by caliper and their area (AB) were calculated. Then, tissue processing of the slabs and the round parts was performed by Tissue prossesor (Leica, Histokinette; Germany) and dipped and molded in paraffin. the samples' order in the templates containing paraffin was in a format that each IUR section of a rat seminal vesicle were put within two or three blocks and pieces of the trocar were individually put inside a block of paraffin to calculate the shrinkage. After completing these steps, 5-micrometer thick sections prepared by microtome and histological staining was performed by hematoxylin-eosin method. The diameter and the area of circular pieces (AA) were measured again after coloring and shrinkage was calculated using the following formula $(20,25)$.

$$
\text { Volume shrinkage }=1-(\mathrm{AA} / \mathrm{AB})^{1.5}
$$

$\mathrm{AA}$ and $\mathrm{AB}$ are the volumes of round parts, respectively, before and after tissue processing, sectioning and staining. After estimating the shrinkage, the final volume of the seminal vesicle was estimated using the following formula $(20,25)$ :

$\mathrm{V}_{\text {final seminal vesicle }}=\mathrm{V}_{\text {primary }} \times(1-$ volume shrinkage $)$

Counting method was used to estimate the volume of tissue and vesicular fluid $(20,27)$, as the density of these components were estimated using optical microscope (Olympus, BX51) and magnification of 10 $\times$. For this purpose, the point probe was thrown randomly on microscopic images and then the points dealt with parenchyma surface or vesicle fluid and whole sections of the seminal bag were counted and their volume fraction ( $\mathrm{Vv}$ ) was estimated by the formula:

$$
V_{V \text { (structuregland })}=\frac{\sum_{i=1}^{n} p_{(\text {structure })}}{\sum_{i=1}^{n} p_{(\text {gland })}}
$$

Where $\sum_{i=1}^{n} P_{\text {(structure) }}$ is the total number of points dealt with profiles parenchyma, or vesicle fluid and $\sum_{i=1}^{n} P_{\text {(gland) }}$ is 
the number of points dealt with all sections of seminal vesicle. Then parenchymal volume and vesicle fluid then were determined by multiplying the bulk density in the final volume of seminal vesicle $(20,27)$.

In order to estimate the volume fraction of the parenchyma components, 10-14 microscopic fields per box was studied with a magnification of $40 \times$. Systematic random selection method was used to select the microscopic field. For example, the position of the first field was randomly selected out of the incisions and then subsequent microscopic fields were selected by moving the microscope field at equal distance along the $\mathrm{X}$ and $\mathrm{Y}$ axis until the study of all slices on a slide. Point counting method and the following formula were used for the calculations $(20,27)$ :

$$
V_{V \text { (structureparenchyma) }}=\frac{\sum_{i=1}^{n} p_{\text {(structure })}}{\sum_{i=1}^{n} p_{\text {(parenchyma })}}
$$

Where $\sum_{i=1}^{n} P_{\text {(structure) }} \quad$ is the total number of points collide with epithelial cells profiles, vessels, connective tissue and smooth muscle tissue and $\sum_{i=1}^{n} P_{\text {(parenchyma) }}$ is the total number of points collide with parenchyma profiles. Volume fraction of each parameter was multiplied by the total volume parenchyma to calculate the volume of the above-mentioned components.

\section{Statistical analysis:}

Statistical analysis of the data, using software (version 16) SPSS and one-way analysis of variance (One-way ANOVA) and Tukey test have been conducted. The difference was considered as significant at the level of $\mathrm{P}<0.05$.

\section{Results}

\section{Histological study of the seminal vesicle:}

Histological studies of seminal vesicle showed that epithelial cells were columnar in the control group and vesicle fluid volume was normal with uniformity and the structure and the thickness of connective and muscle tissue was normal (Figure A -1), but seminal vesicle atrophy, vesicle fluid volume reduction and epithelial cell clutter had been observed in sodium arsenite. In addition, the epithelial cells had been deformed to cylindrical cubic forms and accumulation of abnormal masses of epithelial cells of seminal vesicle gland was observed in some areas of connective tissue, probably due to the loss of cells (Figure B-1). The tissue structure of the group which received sodium arsenite and curcumin simultaneously, was similar to the control group and the vesicle fluid volume had increased to a large extent as compared to sodium arsenite group (Figure C-1). Histological observation in curcumin group showed that normal seminal vesicle structure tissue similar to the control group (Figure D-1).

\section{The mean total volume of seminal vesicle,} parenchymal volume and vesicle fluid volume:

The mean total volume of seminal vesicle and vesicle fluid volume showed a significant reduction in the sodium arsenite group compared to the control group ( $\mathrm{P}<0.001)$ while no significant difference was observed in the comparison of the mean tissue volume in different groups $(\mathrm{P}>0.05)$. A significant increase in mean total volume of seminal vesicle and vesicle fluid volume was observed in sodium arsenite + curcumin group compared to sodium arsenite $(\mathrm{P}<0.001)$ and curcumin was able to reach the value of this parameter the same as in the control group (Table 1).

The average volume of epithelial cells, vascular volume and the volume of connective tissue and muscle:

No significant difference had been observed in the comparison of the average volume of epithelial cells and vascular volume in different groups $(\mathrm{P}>0.05)$. The mean volume of seminal vesicle connective tissue of 
mice treated with sodium arsenite was significantly higher compared with the control group ( $\mathrm{P}<0.001)$. The volume of muscle tissue may also be increased partly in sodium arsenite group compared with the control, but the increase was not significant $(\mathrm{P}>0.05)$.

\section{Body weight and seminal vesicle weight:}

No significant difference has been observed through comparison of the mean body weights of mice in different groups $(\mathrm{P}>0.05)$. Seminal vesicle weight in sodium arsenite group was significantly lower than control $(\mathrm{p}<0.01)$, while curcumin increases seminal vesicle weight in sodium arsenite + curcumin group compared to sodium arsenite $(p<0.05)$. A significant difference was observed through comparison of weight of seminal vesicle treated with sodium arsenite + curcumin and control $(\mathrm{P}>0.05)$ (Table 3$)$.
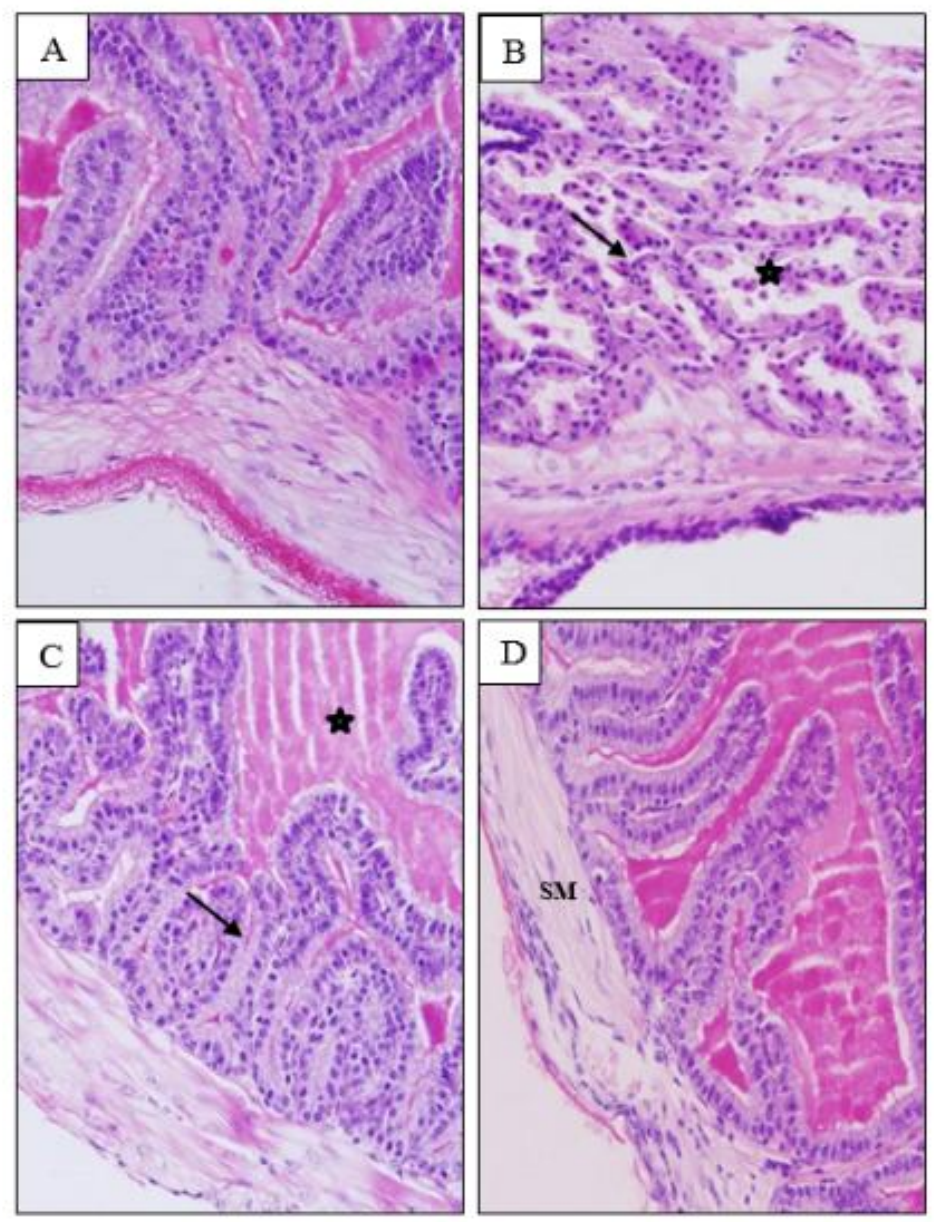

Figure 1. The histological images of the seminal vesicle in different groups of mice 5 weeks after treatment with sodium arsenite ( $5 \mathrm{mg} / \mathrm{kg}$ b.w.), Curcumin $(15 \mathrm{mg} / \mathrm{kg}$ b.w.) and sodium arsenite + curcumin. A) Control group which represents normal seminal vesicle tissue. B) Sodium Arsenite Group, reduction of vesicle fluid (star) and the epithelial secretory destruction (arrows) can be seen. C) Sodium Arsenite + Curcumin Group, Indicative of a similar texture to the control group where an increase in vesicle fluid (star) and the normal secretory epithelium (arrows) can be seen. D) Curcumin Group, the normal structure of the seminal vesicle tissue can be seen. Smooth Muscle (SM) (5-micron slice, H \& E staining, magnification of $40 \times)$. 
Table 1. Comparison of the total seminal vesicle weight, Parenchymal volume and Vesicle fluid volume $\left(\mathrm{mm}^{3}\right)$ in different groups of mice 5 weeks after treatment with sodium arsenite ( $5 \mathrm{mg} / \mathrm{kg} \mathrm{b.w.),} \mathrm{curcumin}(15 \mathrm{mg} / \mathrm{kg} \mathrm{b.w.)} \mathrm{and}$ sodium arsenite + curcumin. Values are as Means \pm SD. Means with different letter codes have significant difference (One-way ANOVA, Tukey's test, $\mathrm{P} \leq 0.05$ ).

\begin{tabular}{lccc}
\hline Groups & Total seminal vesicle weight & Parenchymal volume & Vesicle fluid volume \\
\hline Control & $198.67^{\mathrm{a}} \pm 16.48$ & $46.30^{\mathrm{a}} \pm 5.10$ & $152.37^{\mathrm{a}} \pm 68.11$ \\
Sodium Arsenite & $157.61^{\mathrm{b}} \pm 16.75$ & $52.89^{\mathrm{a}} \pm 7.47$ & $106.38^{\mathbf{b}} \pm 08.13$ \\
Sodium Arsenite + Curcumin & $191.81^{\mathrm{a}} \pm 12.20$ & $47.36^{\mathrm{a}} \pm 3.80$ & $144.45^{\mathrm{a}} \pm 09.34$ \\
Curcumin & $200.90^{\mathrm{a}} \pm 16.76$ & $47.98^{\mathrm{a}} \pm 3.39$ & $152.91^{\mathrm{a}} \pm 14.47$ \\
\hline
\end{tabular}

Table 2. Comparison of the average volume of epithelial cells, vascular volume and the volume of connective tissues and muscles $\left(\mathrm{mm}^{3}\right)$ in different groups of mice 5 weeks after treatment with sodium arsenite $(5 \mathrm{mg} / \mathrm{kg}$ b.w.), curcumin (15mg/kg b.w.) and sodium arsenite + curcumin. Values are as Means \pm SD. Means with different letter codes have significant difference (One-way ANOVA, Tukey's test, $\mathrm{P} \leq 0.05$ ).

\begin{tabular}{|c|c|c|c|c|}
\hline Groups & Epithelial cell volume & Vascular volume & Connective tissue volume & $\begin{array}{c}\text { Muscle tissue } \\
\text { volume }\end{array}$ \\
\hline Control & $29.84^{\mathrm{a}} \pm 3.18$ & $0.66^{\mathrm{a}} \pm 0.09$ & $2.03^{\mathrm{a}} \pm 0.20$ & $14.27^{\mathrm{a}} \pm 2.15$ \\
\hline Sodium Arsenite & $32.78^{\mathrm{a}} \pm 4.42$ & $0.56^{\mathrm{a}} \pm 0.10$ & $2.98^{\mathbf{b}} \pm 0.52$ & $16.54^{\mathrm{a}} \pm 3.15$ \\
\hline Sodium Arsenite + & $28.66^{\mathrm{a}} \pm 3.21$ & $0.60^{\mathrm{a}} \pm 0.11$ & $2.38^{\mathrm{ab}} \pm 0.27$ & $15.67^{\mathrm{a}} \pm 1.71$ \\
\hline \multicolumn{5}{|l|}{ Curcumin } \\
\hline Curcumin & $29.13^{\mathrm{a}} \pm 3.17$ & $0.65^{\mathrm{a}} \pm 0.09$ & $2.34^{\mathrm{a}} \pm 0.28$ & $15.93^{\mathrm{a}} \pm 1.73$ \\
\hline
\end{tabular}

Table 3. Comparison of body weight and seminal vesicle weight $(\mathrm{g})$ in different groups of mice 5 weeks after treatment with sodium arsenite $(5 \mathrm{mg} / \mathrm{kg}$ b.w.), curcumin $(15 \mathrm{mg} / \mathrm{kg}$ b.w.) and sodium arsenite + curcumin. Values are as Means \pm SD. Means with different letter codes have significant difference (One-way ANOVA, Tukey's test, $\mathrm{P} \leq 0.05$ ).

\begin{tabular}{lcc}
\hline Groups & Body weight & Seminal vesicle weight \\
\hline Control & $35.71^{\mathrm{a}} \pm 1.97$ & $0.24^{\mathrm{a}} \pm 0.02$ \\
Sodium Arsenite & $33.79^{\mathrm{a}} \pm 1.87$ & $0.19^{\mathrm{b}} \pm 0.03$ \\
Sodium Arsenite + Curcumin & $34.62^{\mathrm{a}} \pm 2.30$ & $0.23^{\mathrm{a}} \pm 0.01$ \\
Curcumin & $34.23^{\mathrm{a}} \pm 2.43$ & $0.25^{\mathrm{a}} \pm 0.03$ \\
\hline
\end{tabular}

\section{Discussion}

The present study showed that the weight, the volume of seminal vesicle and vesicle fluid volume in mice of sodium arsenite had significant decrease compared to the control group and the amount of connective tissue showed significant increase and treatment with curcumin was able to compensate the factor in the control group. Other researchers reported seminal vesicle atrophy and weight loss in laboratory animals treated with sodium arsenite (1-3). Seminal Vesicles Atrophy is mainly in connection with reduced androgens that manifests as wrinkling and reduced size of the seminal vesicles and histologically is along with a reduction in the release of seminal vesicle, the destruction of the epithelium and increment of musclefiber stroma (28). 
Weight loss of Seminal vesicle as a tumor responsible for nutrients discharge of seminal fluid shows the impression of epithelial cell secretions by treatment with sodium arsenite. The decline in testosterone levels in animals treated with arsenic is the most important cause of seminal vesicle secretion $(6$, 10, 29). On the other hand, Reactive Oxygen Species (ROS) such as superoxide anion radicals and hydrogen peroxide $\mathrm{H}_{2} \mathrm{O}_{2}$ plays an important role in the development of endocrine disorders due to environmental chemicals and inhibits steroidogenesis in the testis (30). Sodium arsenite causes hormonal imbalance (31). Arsenic levels inhibit steroidogenesis and reduce the level of testosterone in the testicles by increasing mitochondrial ROS and reduction of the

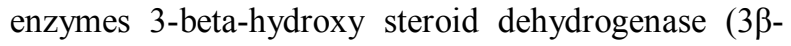
Hydroxysteroid dehydrogenase: 3 $\beta$-HSD), 17-betahydroxy steroid dehydrogenase (17 $\beta$-Hydroxysteroid dehydrogenase: 17 $\beta$-HSD) as an enzyme involved in the biosynthesis of steroid hormones.

Also, arsenic may reduce the levels of testosterone in the Leydig cells by reducing mRNA expression of StAR protein (steroidogenic acute regulatory protein) and cytochrome P450scc (Cholesterol side-chain cleavage enzyme) $(7,10)$. StAR protein is essential for the synthesis of testosterone and is responsible for transporting cholesterol to the inner mitochondrial Leydig cells. P450scc cytochrome enzyme in P450 cytochrome group is involved in the conversion of cholesterol to pregnenolone in the inner mitochondrial membrane of Leydig cells and is the first enzymatic step in the biosynthesis of testosterone (32). The decrease in both expressions by arsenic leads to a decrease in testosterone synthesis. According to the above researches, it can be said that sodium arsenite reduces testosterone levels by several mechanisms, resulting in dysfunction in the seminal vesicle as an androgen-dependent organ. Androgenic steroids can lead to structure adjustment and function of the seminal vesicles, inhibition of apoptosis of epithelial cells and stimulation of cell proliferation in these organs (33). In addition, testosterone induces the secretion of fluids and electrolytes in the seminal vesicles. Seminal vesicle contains high levels of 5-alpha-reductase enzyme that indicates the ability of the organs in the conversion of testosterone to dihydrotestosterone (DHT) (21). As reported, the concentration of DHT is 8 times higher than testosterone in the rat seminal vesicle (33). DHT can affect the volume and viscosity of semen and leads to up-regulation of mRNA of seminal vesicles secreted proteins (21). The decrease in testosterone and subsequently DHT by sodium arsenite can reduce the secretion of the seminal vesicles. Fructose is a monosaccharide, an important material synthesized and secreted by the seminal vesicles and involves in the development of energy metabolic. It was found that sodium arsenite can reduce the formation ability of fructose by seminal vesicle (6). Fructose synthesis is regulated by androgens and is directly associated with testosterone levels (34). As in a study, Wistar rats' treatment with arsenic trioxide to the amount of $3 \mathrm{mg} / \mathrm{kg} /$ day for 28 days showed a significant decrease in the fructose content of the seminal vesicle, and dysfunction of the organ in addition to the seminal vesicle weight loss (6). Thus, sodium arsenite leads to lower seminal vesicle secretions by reducing the level of testosterone and reduces the vesicle fluid volume and causes atrophy of seminal vesicle.

The results of the body weight showed that there was not significant difference between the treatment and control groups at the end of the treatment period. These results indicate that $5 \mathrm{mg} / \mathrm{kg} /$ day sodium arsenite treatment of adult mice for 35 days has a significant impact on the metabolic activity of mice and thus a change in weight. This result is in line with the results of some previous studies $(8,9,11)$. However, some studies have reported body weight loss 
in the animals treated with sodium arsenite $(1,2,3,25)$. The differences in the results might be due to treatment duration or the dose of arsenic (8).

As noted in the study, curcumin in the mice receiving sodium arsenite and curcumin simultaneously, increases the weight and volume of the seminal vesicle, increases the size of the vesicle fluid and reduces the volume of connective tissue normally. In certifying the results of the present study, in 2013, Khan and his colleagues showed that curcumin treatment leads to a significant increase in seminal vesicle weight as in the control group. In addition, curcumin improves parameters associated with oxidative stress, increases enzyme activity in the testes, increases mRNA expression of 17 $\beta$-HSD and CYP450scc enzymes and level of testosterone in the testes of rats (10). Other studies indicate a protective effect of curcumin on the seminal vesicle tissue in laboratory animals treated with various pesticides which is in agreement with our results. So that intraperitoneal of $20 \mathrm{mg} / \mathrm{kg} /$ day of curcumin for 26 days can increase the seminal vesicle weight and serum testosterone levels in rats treated with chromium (14). It was shown in another study that simultaneous administration of curcumin and metronidazole could prevent reduction in the size of the seminal vesicle, and vesicular fluid due to metronidazole in mice (20). In addition, curcumin improves the activity of $17 \beta$-HSD and $3 \beta$ - HSD enzymes in the rats treated with aflatoxin (35). The results of various studies have shown that curcumin is a strong antioxidant, and one of the most powerful free radical cleansings and increases intracellular glutathione, which is capable of producing different kinds of ROS in vivo and in vitro $(14,15)$. In

\section{References:}

1- Adil M, Visnagri A, Kumar VS, Kandhare AD, Ghosh P, Bodhankar SL. Protective Effect of Naringin on Sodium Arsenite Induced Testicular Toxicity via fact, the presence of beta-Dy-ketone phenolic groups and methoxy groups in curcumin plays a role in free radical scavenging activity (36). By maintaining the activity of antioxidant enzymes such as superoxide dismutase, catalase and glutathione peroxidase in high levels, curcumin can reduce the lipid peroxidation (37). In addition, curcumin inhibits the oxidation of the thiol groups (38). The protection of the sexual glands antioxidant not only is due to their antioxidant capacity improvement, but also due to restructuring and adjustment of osteogenesis against the toxicity of arsenic (6).

The effect of curcumin against the toxicity of sodium arsenite on seminal vesicle had been studied for the first time in the present study. Results showed that curcumin could improve the histopathological lesions induced by sodium arsenite on the seminal vesicle tissue and possibly curcumin applies the effect by increasing the antioxidant defense and improving androgen levels. However, it is suggested to measure the effects of curcumin on serum testosterone level of rats treated with sodium arsenite in addition to measuring the levels of antioxidant enzymes to determine the exact mechanism of the effect of curcumin and sodium arsenite on seminal vesicle.

\section{Acknowledgments}

This research project sponsored by the Department of Research and Technology, University of Arak. In this way we want to express our thanks and appreciation to the relevant authorities of whom our research project became possible with their support. Our thanks and gratitude to Mrs. Samira Naderi who cooperated in this research.

Modulation of Biochemical Perturbations in

Experimental Rats. Pharmacologia 2014; 5(6): 222-34. 
2- Pant N, Kumar R, Murthy RC, Srivastava SP. Male reproductive effect of arsenic in mice. Biometals 2001; 14 (2): 113-7.

3- Monika T, Vijaya Bhaskara Reddy M. Sasikala P. Sodium arsenite induced male reproductive toxicity in rats. IJAST 2013; 4(3): 296-302.

4- Knowles FC, Benson AA. The biochemistry of arsenic. Trends Biochem Sci 1983; 8(5): 178-80.

5- Shi H, Shi X, Liu KJ. Oxidative mechanism of arsenic toxicity and carcinogenesis. Mol Cell Biochem 2004; 255(1-2): 67-78.

6- Banik GN, Chakraborty I, Mukhopadhyay P. Ameliorative Effect of $\alpha$-tocopherol and Ascorbic Acid on the Accessory Reproductive Glands of Adult Male Rats in Arsenic Toxicity. Int J Pharm Sci Rev Res 2014; 26(2): 282-7.

7- Nath A, Anshu AK, Priyanka, Singh CK, Behera S, Singh JK. Reprotoxicity and genotoxicity by arsenic ensuing to male infertility in male Mus musculus. IJPSR 2017; 8(3): 1153-9.

8- Momeni HR, Oryan S, Eskandari N. Effect of vitamin E on sperm number and testis histopathology of sodium arsenite-treated rats. Biol Reprod 2012; 12(2): 172-81.

9- Sarkar M, Chaudhuri GR, Chattopadhyay A, Biswas NM. Effect of sodium arsenite on spermatogenesis, plasma gonadotrophins and testosterone in rats. Asian $\mathrm{J}$ Androl 2003; 5(1), 27-31.

10- Khan S, Telangb AG, Malika JK. Arsenic-induced oxidative stress, apoptosis and alterations in testicular steroidogenesis and spermatogenesis in wistar rats: ameliorative effect of curcumin. Wudpecker Journal of Pharmacy and Pharmocology 2013; 2(3): 33-48.

11- Jana K, Jana S, Samanta PK. Effects of chronic exposure to sodium arsenite on hypothalamo-pituitary-testicular activities in adult rats: possible an estrogenic mode of action. Reprod Biol Endocrinol 2006; 4: 9.

12- Aggarwal BB, Kumar A, Aggarwal MS, Shishodia S. Curcumin derived from turmeric (Curcuma longa): a spice for all seasons. Phytopharmaceuticals in cancer chemoprevention 2005;23:351-87.

13- Kumar A, Dora J, Singh A. A review on spice of life Curcuma longa (Turmeric). Int J Appl Biol Pharm 2011; 2(4): 371-9.

14- Chandra AK, Chatterjee A, Ghosh R, Sarkar M. Effect of curcumin on chromium-induced oxidative damage in male reproductive system. Environ Toxicol Pharmacol 2007; 24(2): 160-6.

15- El-Wakf M, Elhabiby ME, El-kholy WM, El-Ghany EA. Use of Tumeric and Curcumin to Alleviate Adverse Reproductive Outcomes of Water Nitrate Pollution in Male Rats. Nature Sci 2011; 9(7): 229-39.

16- Mathuria N, Verma RJ. Curcumin ameliorates aflatoxininduced lipid peroxidation in liver, kidney and testis of mice--an in vitro study. Acta Pol Pharm 2007; 64(5): 413-6.

17- Aktas C, Kanter M, Erboga M, Ozturk S. Anti-apoptotic effects of curcumin on cadmium-induced apoptosis in rat testes. Toxicol Ind Health 2012; 28(2): 122-30.

18- Gouda SG, Khalil MS, Naim MM. Curcumin protects against testicular damage and genotoxicity induced by acrylamide in male albino mice. Egyptian J Histol 2011; 34(2): 333-45.

19- Sharma P, Singh R. Protective role of curcumin on lindane induced reproductive toxicity in male Wistar rats. Bull Environ Contam Toxicol 2010; 84(4): 378-84.

20- Noorafshan A, Karbalay-Doust S. Curcumin protects the seminal vesicle from metronidazole-induced reduction of secretion in mice. Acta Medica (hradec Králové) 2012; 55: 32-6.

21- Ramli NS, Giribabu N, Muniandy S, Salleh N. Testosterone regulates levels of Cystic Fibrosis transmembrane regulator, adenylate cyclase and cAMP in the seminal vesicles of orchidectomized rats. Theriogenology 2016; 85(2): 238-46.

22- Pang SF, Chow PH, Wong TM. The role of the seminal vesicles, coagulating glands and prostate glands on the 
fertility and fecundity of mice. J Reprod fert 1979; 56(1): 129-32.

23- El-Demerdash FM, Yousef MI, Radwan FM. Ameliorating effect of curcumin on sodium arseniteinduced oxidative damage and lipid peroxidation in different rat organs. Food Chem Toxicol 2009; 47 (1): 249-54.

24- Yousef MI, El-Demerdash FM, Radwan FM. Sodium arsenite induced biochemical perturbations in rats: ameliorating effect of curcumin. Food Chem Toxicol 2008; 46(11): 3506-11.

25- Soleimani Mehranjani M, Taefi R. The protective role of vitamin $\mathrm{E}$ on the testicular tissue in rats exposed to sodium arsenite during the prenatal stage till sex maturity: A stereological analysis. Iran J Reprod Med 2012; 10(6): 571-80.

26- Mouton PR. Length and surface area. In: Mouton PR, Editor. Principles and practices of unbiased stereology: an introduction for bioscientists. Baltimore, Maryland: Johns Hopkins University Press; 2002. P. 103-5.

27- Howard CV, Reed MG. Unbiased stereology: threedimentional measurement in microscopy. Microscopy handbook series 41. United Kingdom: Bios Scientific Publishers; 1998.

28- Tucker MJ. The Male Genital System, In: Diseases of the Wistar Rat, London: Taylor \& Francis; 2003. P. 163177.

29- da Silva RF, dos Santos Borges C, Silva PV, Missassi G, Kiguti LRA, Pupo, AS, et al. The Coadministration of N-Acetylcysteine Ameliorates the Effects of Arsenic Trioxide on the Male Mouse Genital System. Oxid Med Cell Longev 2016; 2016: 1-11.

30- Omura T, Morohashi K. Gene regulation of steroidogenesis. J Steroid Biochem Mol Biol 1995; 53(1-6): 19-25.
31- Davey JC, Nomikos AP, Wungjiranirun M, Sherman JR, Ingram L, Batki C, et al. Arsenic as an Endocrine Disruptor: Arsenic Disrupts Retinoic Acid Receptor-and Thyroid Hormone Receptor-Mediated Gene Regulation and Thyroid Hormone-Mediated Amphibian Tail Metamorphosis. Environ Health Perspect 2008; 116(2): 165-72.

32- Miller WL. StAR Search-What we know about how the steroidogenic acute regulatory protein mediates mitochondrial cholesterol import. Mol Endocrinol 2007; 21: 589-601.

33- Kashiwagi B, Shibata Y, Ono Y, Suzuki K, Honma S, Yamanaka H. Effect of androgen concentration on seminal vesicle blood flow in rats-establishment of new highly sensitive simultaneous androgen measurement method. Urology 2005; 66: 218-23.

34- Bustos-Obregon E, Esponda P, Sarabia L. Effect of flutamide in mouse spermatogenesis and on the function of seminal vesicle and prostate. Int J Morphol 2006; 24(2): 171-4.

35- Verma RJ, Mathuria N. Effect of curcumin on aflatoxininduced biochemical changes in testis of mice. Fertile Steril 2009; 91(2): 597-601.

36- García-Niño WR, Pedraza-Chaverrí J. Protective effect of curcumin against heavy metals-induced liver damage. Food and Chemical Toxicology 2014; 69: 182-201.

37- Reddy AC, Lokesh BR. Studies on spice principles as antioxidants in the inhibition of lipid peroxidation of rat liver microsomes. Mol Cell Biochem 1992; 111(1-2): 117-24.

38- Manikandan P, Sumitra M, Aishwarya S, Manohar BM, Lokanadam B, Puvanakrishnan R. Curcumin modulates free radical quenching in myocardial ischaemia in rats. Int J Biochem Cell 2004; 36: 1967-80. 